\title{
TAo TAVI + OPCABG: a new hybrid option
}

\author{
Andrew Brazier ${ }^{1 *}$, Imthiaz Manoly ${ }^{1}$, Doug Fraser ${ }^{2}$, Ragheb Hasan ${ }^{1}$ \\ From World Society of Cardiothoracic Surgeons 25th Anniversary Congress, Edinburgh \\ Edinburgh, UK. 19-22 September 2015
}

\section{Background/Introduction}

Hybrid surgical approaches are gaining popularity. Minimally invasive aortic valve replacement and percutaneous coronary intervention $[\mathrm{PCI}]$ is well documented. We wanted to explore the feasibility of trans-catheter aortic valve implantation [TAVI] and off pump coronary artery bypass grafts [OPCAB].

\section{Aims/Objectives}

We proposed that in TAVI patients where PCI is not possible or has failed, trans-aortic TAVI with concomitant $\mathrm{OPCAB}$ would be a suitable alternative.

\section{Method}

A 77 year old man admitted following an out of hospital cardiac arrest was found to have an occluded left anterior descending (LAD) artery, a patent stent in a dominant circumflex and a small diseased right coronary. Past medical history included myocardial infarctions on four occasions, PCI, and severe left ventricular failure. Echocardiography demonstrated severe, calcific aortic stenosis and poor left ventricular function. The multi-disciplinary team recommended TAVI. Work up identified abdominal aortic aneurysm which precluded trans-femoral TAVI approach. A perfusion scan confirmed viable myocardium in the LAD territory. He was put forward for trans-aortic TAVI with OPCAB surgery (left internal mammary artery to $\mathrm{LAD})$.

\section{Results}

The procedure was performed as planned without any complications. Post-operative echocardiogram confirmed a well-placed valve. The patient was treated for a chest infection and discharged home on 8 th post-operative day. He was seen at the outpatient clinic at 8 weeks and was asymptomatic and with good exercise tolerance.

'Department of Cardiothoracic surgery, Manchester Royal Infirmary, Manchester, M13 9WL, UK

Full list of author information is available at the end of the article

\section{Discussion/Conclusion}

Trans-aortic TAVI and OPCAB is a potential alternative to conventional aortic valve replacement and coronary artery bypass surgery as well as the hybrid approach of minimally invasive aortic valve replacement and PCI.

\section{Consent}

Written informed consent was obtained from the patient's next of kin for publication of this abstract and any accompanying images. A copy of the written consent is available for review by the Editor of this journal.

\section{Authors' details}

'Department of Cardiothoracic surgery, Manchester Royal Infirmary, Manchester, M13 9WL, UK. ${ }^{2}$ Department of Cardiology, Manchester Royal Infirmary, Manchester, M13 9WL, UK.

Published: 16 December 2015

doi:10.1186/1749-8090-10-S1-A24

Cite this article as: Brazier et al:: TAo TAVI + OPCABG: a new hybrid

option. Journal of Cardiothoracic Surgery 2015 10(Suppl 1):A24.
Submit your next manuscript to BioMed Central and take full advantage of:

- Convenient online submission

- Thorough peer review

- No space constraints or color figure charges

- Immediate publication on acceptance

- Inclusion in PubMed, CAS, Scopus and Google Scholar

- Research which is freely available for redistribution 